\title{
Os ambientes, a pesca e a gestão das pescarias da piramutaba (Brachyplatystoma vaillantii) no Estuário Amazônico-PA
}

The environments, fisheries and fisheries management of piramutaba (Brachyplatystoma vaillantii) in the Amazon Estuary-PA

Márcia Melo Ramos - Mestre em Ciências do Ambiente e Sustentabilidade na Amazônia pela Universidade Federal do Amazonas (UFAM) em 2010. E-mail: marcmel@hotmail.com

Henrique dos Santos Pereira - PhD em Ecologia pela Pennsilvania State University em 1999, professor Associado da Universidade Federal do Amazonas, atuando no PPG em Ciências Ambientais. E-mail: hsp2@argo.com.br

\section{Resumo}

Este estudo tem como objetivo identificar os ambientes, a intensidade da sua produção e a gestão no Estuário Amazônico. As informações utilizadas neste trabalho foram obtidas a partir de pesquisas bibliográficas e questionários aplicados aos atores da pesca. Os resultados mostraram que a piramutaba é explorada tanto pela pesca artesanal quanto industrial na área do Estuário Amazônico. A produção das pescarias na área atingiu 16.063,50 toneladas em 1999, caiu para 12.010,00 toneladas no ano seguinte e atingiu o pico de produção de 24.701,00 toneladas em 2006. A análise da tendência da produção conforme a avaliação dos atores da pesca indica diminuição dos estoques nos últimos 10 anos e que a perspectivas futuras para a produção das pescarias artesanais e industriais apontam que haverá diminuição dos desembarques na área do Estuário.

\section{Palavras-chave}

Piramutaba. Pescaria. Estuário. ambiente.

\begin{abstract}
This study aims to identify the environments, the intensity of their production and management actions in the Amazon Estuary. Information used in this study was obtained from literature reviews and questionnaires applied to diverse stakeholder's groups of piramutaba fisheries. The results showed that the piramutaba is exploited by both industrial and artisanal fisheries in the area of the Amazon Estuary. The production of fisheries in the area totaled 16,063.50 tons in 1999 , fell to $12,010.00$ tons in the following year and reached peak production of $24,701.00$ tons in 2006. As indicated by the actor's assessments of fishing stocks the production presented a decrease in the last 10 years and it is expected that the landings of artisanal and industrial fisheries in the Estuary area will be reduced.
\end{abstract}

\section{Keywords}

Piramutaba. Fishing. Estuary. Environment. 


\section{INTRODUÇÃO}

A bacia amazônica é uma região hidrográfica composta de igarapés, rios, lagos, canais e furos, onde estão abrigados cerca de 20,0\% de toda água doce da superfície da terra. Essa bacia abriga uma grande diversidade de espécies de peixes e uma grande variedade de solos e comunidades vegetais oferecendo uma abundância de nichos aquáticos e terrestres em seus 7 milhões de $\mathrm{km}^{2}$ (SMITH, 1979). A atividade pesqueira possui um papel fundamental nessa região e constitui-se em fonte de alimento, renda, comércio e lazer para a grande parte da população que reside às margens dos rios de médio a grande porte (SANTOS e SANTOS, 2005).

$\mathrm{Na}$ costa norte do Brasil, os rios Amazonas e Tocantins deságuam no Oceano Atlântico entre os estados do Pará e Amapá. Esta localidade, chamada de Estuário ou Delta Amazônico, estende-se na linha da costa destes estados, formando um complexo ambiente aquático de alta produtividade biológica, suportando uma biomassa de espécies de peixes exploradas por frotas pesqueiras artesanais e industriais. (OLIVEIRA; FREDÓU; LUCENA, 2007).

A piramutaba (Brachyplatystoma vaillantii) ocorre na costa norte do Brasil e possui uma ampla distribuição nas bacias do Norte da América do Sul, existindo registros de sua ocorrência desde a bacia do Orinoco, na Venezuela, até a bacia do rio Parnaíba, na divisa dos estados do Maranhão e Piauí (MEES, 1974; CHAVES et al., 2003). Segundo Batista et al. (2005), esta espécie se reproduz nas cabeceiras de vários braços (afluentes) dos rios Amazonas (Juruá, Purus, Madeira, Içá, Japurá e outros) e alimenta-se no Estuário, em Belém, e cresce na Amazônia Central (Almerim, Santarém, até Manaus).

No estado do Pará, a exploração industrial da piramutaba iniciou-se no ano de 1971 com o emprego de barcos camaroneiros ajustados para a pesca de peixes demersais (IBAMA, 1997; CHAVES et al., 2003). Segundo IBAMA (1997), a exploração dessa espécie era exclusivamente artesanal e em pequena escala, sendo que a produção consumida era exclusivamente para o mercado interno.

Segundo o Relatório do Censo Estrutural da Região Norte - CEPNOR (2006), em 1980, foram observadas quedas significativas nas capturas de alguns estoques de peixes tradicionalmente explorados, especialmente a piramutaba. A produção industrial dessa espécie, na área do estuário, atingiu 20 mil toneladas em 1977 e caiu para 15 mil toneladas em 1987, chegando a 10 mil toneladas no mesmo ano (TORRES; SILVA; BUENNDIA, 1995; CEPNOR, 2006).

O presente trabalho teve como objetivo identificar os ambientes de pesca, a intensidade da sua produção e a ações de manejo da piramutaba (Brachyplatystoma vaillantii) no Estuário Amazônico gerando informações para a compreensão das atividades pesqueiras, essenciais ao desenvolvimento de um plano integrado de manejo da espécie. 


\section{MATERIAIS E MÉTODOS}

\section{Área de Estudo}

A área de estudo abrangeu quatro municípios que pertencem ao estado do Pará, sendo dois localizados na ilha do Marajó: Salvaterra e Soure; um na extensão do Salgado, Vigia; e um em Belém, no distrito de Icoaraci (Figura 1).

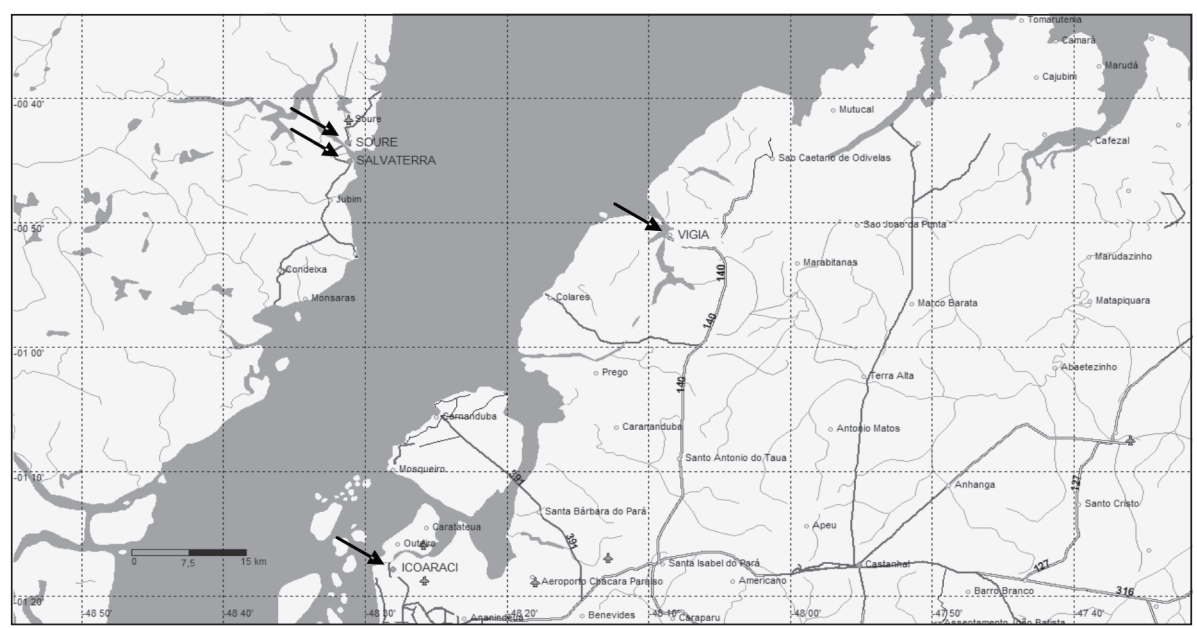

Figura 1: Imagem e localização geográfica da área de estudo.

Fonte: Programa TrackMaker, 2010.

\section{Coleta de Dados}

As informações utilizadas neste trabalho foram baseadas em pesquisas bibliográficas e questionários estruturados aplicados por um entrevistador aos pescadores artesanais, industriais, gestores e pesquisadores. As entrevistas dos pescadores foram feitas pessoalmente. Já para os gestores e pesquisadores, os questionários foram enviados via correspondência eletrônica.

As perguntas dos questionários foram feitas sobre dois períodos de tempo (passado e futuro) para verificar a opinião dos entrevistados sobre a situação da produção das pescarias da piramutaba nos últimos e nos próximos 10 anos.

As variáveis coletadas nas entrevistas e questionários versaram sobre a opinião dos atores sociais da pesca quanto a tendências da produção pesqueira artesanal e industrial da piramutaba e outras questões sobre os fatores ambientais e socioeconômicos considerados determinantes para a produção pesqueira passada e futura. Para isso, foi utilizada uma adaptação da metodologia ParFish, que tem como objetivo entender mais sobre o recurso e desenvolver ações de gestão com base nesse conhecimento que envolva os beneficiadores do recurso. 
Os resultados esperados do processo ParFish dão uma melhor compreensão da pesca e do estado das ações e metodologias para uma melhor gestão de acordo entre as partes interessadas, tais como: esforço, quota ou controles de área fechada, planos de monitoramento e projetos-piloto para testar as opções de gestão ou melhorar a coleta de dados (WALMSLEY; HOWARD; MEDLEY, 2005).

Para orientar os entrevistados e garantir a coerência interna dos dados, adotaram-se os seguintes conceitos:

1 Sentido da variação (aumentou, diminuiu, não variou): avaliar o sentido da variação de cada fator quanto à resposta;

2 Intensidade da variação (muito, pouco, nula): verificar o grau da intensidade de cada fator de acordo com a resposta;

3 Grau de certeza da informação (muito certo, pouco certo, não certo): avaliar o grau de certeza do entrevistado quanto à sua análise da influência de cada fator;

3.1 Muito certo: considero-me bem informado e seguro quanto à análise feita;

3.2 Pouco certo: considero-me estar informado, porém, não totalmente seguro quanto à análise feita;

3.3 Não certo: considero-me pouco certo ou nada informado sobre o tema e inseguro quanto à análise feita.

Foram realizados levantamentos de dados secundários da produção pesqueira da piramutaba desembarcada no porto de Belém, buscados através do banco de dados do Instituto Brasileiro do Meio Ambiente e dos Recursos Naturais Renováveis (IBAMA) e literaturas referentes à pesca da espécie.

Para os pescadores artesanais, também foram realizadas entrevistas específicas através de questões elaboradas relativas aos ambientes de pesca. E, com auxílio de um mapa impresso e ampliado do Google Earth 2010, foi feita a identificação desses ambientes na área do Estuário.

Para as pescarias industriais foram disponibilizadas, pelas empresas situadas em Belém, no Distrito de Icoaraci, as georreferências da área de atuação da frota industrial.

A pesquisa de campo foi realizada nos meses de outubro e dezembro de 2009, sendo que neste último mês acontece o início da safra da piramutaba. Em cada pesquisa, no caso dos pescadores artesanais, optou-se por entrevistar pescadores mais experientes que estivessem envolvidos, especificamente, nas pescarias de piramutaba. 


\section{Análise dos dados}

$\mathrm{Na}$ análise dos dados, foi utilizada a estatística descritiva com o objetivo de resumir uma série de valores de mesma natureza, fazendo com que se tenha uma visão global da variação destas estimações.

\section{RESULTADOS E DISCUSSÃO}

\section{Ambientes de pesca da piramutaba}

Foi obtido um total de 35 entrevistas para os grupos de interesse, sendo que 25 foram realizadas com pescadores artesanais e industriais e 11 para os gestores e pesquisadores.

Segundo os entrevistados, a piramutaba se encontra nos rios Pará, Amazonas e no Estuário que vai até a costa do Amapá. Conforme os pescadores industriais e artesanais, a frota industrial atua na área próxima à costa do Amapá, enquanto que as pescarias artesanais estão mais próximas à costa da ilha do Marajó. As pescarias artesanais são realizadas próximas às ilhas Machadinho e Mexiana, e a noroeste da ilha de Marajó, nos municípios de Chaves e Afuá (Figura 2). De acordo com o relato dos pescadores industriais, a operação da frota pesqueira é realizada no litoral Norte entre a Guiana Francesa e a fronteira do Brasil, no estado do Maranhão.

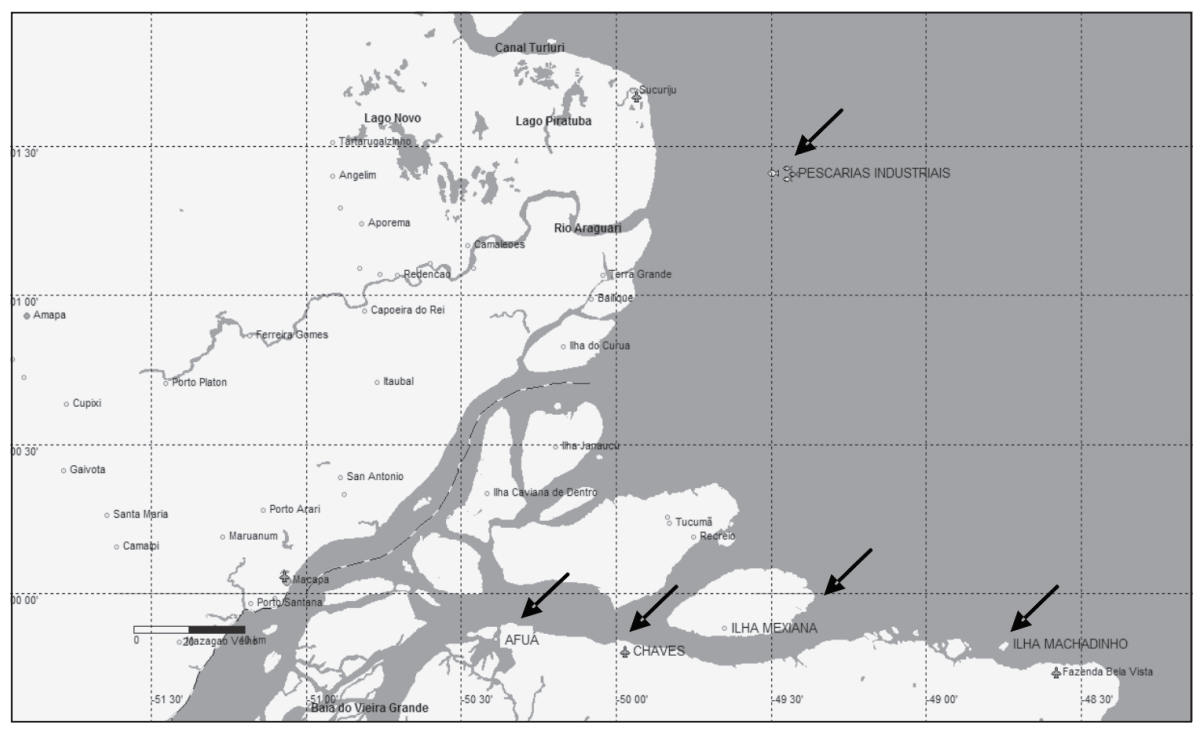

Figura 2: Locais de pesca identificados por pescadores industriais e artesanais. Fonte: Programa TrackMaker, 2010. 
Segundo Barthem (2003), um pesqueiro pode significar um ponto geográfico. No entanto, na maioria das vezes, a localização do pesqueiro é mostrada como uma área de diferentes tamanhos que pode ser: um grande lago, um complexo de lagos, um rio ou uma região de costa. Barthem (2003) em seu estudo na região da bacia amazônica agrupou as áreas de pesca em categorias de regiões, sendo estas: rio Amazonas, rio Tocantins, Delta Interno e Estuário e Costa, e em outro estudo mais antigo Barthem e Petrere (1995) dividiram essas áreas em Norte, correspondendo à costa do Amapá ao norte da foz do rio Araguari; foz amazônica propriamente dita; baía do Marajó; e Salgado, a costa do Pará.

De acordo com o mesmo autor, o estuário é o principal habitat explorado pela pesca da piramutaba no estado do Pará. Segundo Barthem e Goulding (1997), este ambiente é formado pelo rio Amazonas ao norte e pelo rio Tocantins ao sul. As águas do rio Amazonas chegam à parte sul do Estuário por meio do canal de Breves, que desemboca no rio Pará que é um tributário do rio Tocantins.

No ambiente estuarino existe uma extensa zona de mistura ao norte e a leste da ilha de Marajó, na qual a produção de algas é muito grande. As águas dos rios Amazonas e Tocantins fornecem nutrientes, diretamente ou por meio de matéria orgânica, e as águas oceânicas claras permitem a entrada de luz indispensável para a intensa produção de algas. Devido à alta produtividade primária, esta área serve como local de criação de grandes bagres, especialmente a piramutaba e atrai pescarias distintas como: as pescarias artesanais e industriais (BARTHEM; GOULDING, 1997).

As áreas identificadas pelos pescadores industriais e artesanais neste estudo coincidem com o descrito por Barthem e Petrere (1995). Segundo Mourão, Pinheiro e Lucena (2007), na época das chuvas, com o deslocamento das águas do rio Amazonas, a piramutaba margeia toda a costa da ilha do Marajó, adentra no rio Pará e chega até o município de Soure, no qual passa a ser capturada em menor escala pelas pescarias artesanais.

Uma lei brasileira pró́be a pesca de arrasto a menos de 10 milhas da costa, concordando com a Portaria NR-R-11, de 13 de maio de 1987, publicada no Diário Oficial da União no dia 14/05/1987 (AVIZ, 2006). De acordo com este mesmo autor, a região localizada acima de $05^{\circ}$ ao Norte não pode ser frequentada por pescarias brasileiras porque essa área pertence a outro país (Guiana Francesa). Na parte intermediária do Estuário do rio Amazonas, no período do inverno, a pesca da piramutaba é efetuada em escala industrial.

\section{Produção pesqueira e a avaliação dos grupos de interesse}

A análise da percepção da tendência da produção das pescarias da piramutaba indica que, para os pescadores, houve diminuição dos estoques nos últimos 10 anos 
na área do Estuário Amazônico. Os resultados da opinião dos entrevistados sobre o estado da produção pesqueira artesanal dessa espécie indicam que a avaliação preponderante é a de que a produção das pescarias artesanais diminuiu muito, enquanto que dentre os pescadores industriais, a opinião majoritária foi a de que os desembarques dessa espécie diminuiram bastante. Os informantes mostraram estar muito certos dessa análise.

A maioria dos entrevistados, especialmente os pescadores artesanais e ex-pescadores industriais de Vigia, Salvaterra e Soure, relatou que antigamente "dava muita piaba" (termo utilizado para referir a piramutaba) e que na atualidade a pressão da frota industrial sobre esses estoques aumentou significativamente devido ao seu alto poder de pesca. Os mesmos chamam a frota industrial de "grandes barcas". Segundo eles, essas "grandes barcas" variaram expressivamente no decorrer do tempo. Dias Neto (c.p.) discorre que a frota industrial era composta em princípio de barcos para arrasto de parelhas (dois barcos arrastando uma rede), em seguida para trilheira (três barcos arrastando duas redes), logo para quadrilheira (quatro barcos arrastando três redes) e até quinquilheira (cinco barcos arrastando quatro redes).

Quanto às perspectivas futuras para a produção das pescarias artesanais e industriais da piramutaba, a maioria dos pescadores entrevistados acredita que haverá diminuição dos desembarques na área do estuário. As opiniões se dividem quanto à intensidade dessa diminuição. Opiniões com maior grau de certeza (muito certo) estão associadas com avaliações que apontam para uma diminuição mais acentuada. Outros entrevistados relataram que a produção das pescarias artesanais não irá variar, se tornará estável mostrando não estar muito certos dessa análise.

No período de dez anos, entre 1999 e 2008, os desembarques de piramutaba nos estados do Amazonas e Pará oscilaram entre 20.000 e 25.000 toneladas, com exceção de um pico em 2006, quando a produção alcançou mais de 28.000 toneladas. E a produção da pesca industrial e artesanal da piramutaba no Estuário Amazônico atingiu 16.063,50 toneladas em 1999, caiu para 12.010,00 toneladas no ano seguinte e atingiu o pico de produção de 24.701,00 toneladas em 2006.

Segundo os dados de estatística da pesca (IBAMA, 2007), a região Norte, no ano de 2007, produziu 139.966 toneladas de pescado, com um valor total estimado de $\mathrm{R} \$ 357.988 .790,00$. É a maior produção da pesca extrativa continental do Brasil, apesar de um decréscimo de 5,4\% quando comparada ao ano de 2006. Naquele ano, a pesca na região Norte correspondeu a $57,5 \%$ da produção da pesca continental do país. A produção pesqueira da região Norte é desenvolvida em função do rio Amazonas que despeja um grande volume de água doce, com elevada quantidade de material de origem terrestre em suspensão que, ao se depositar sobre a plataforma 
continental da foz daquele rio, faz com que a costa dos estados do Pará e Amapá apresentem alta produtividade, especialmente de comunidades do fundo do mar (ANON, 2002; BATISTA et al., 2005).

De acordo com os dados da estatística pesqueira efetuadas pelo IBAMA, os mesmos mostraram que o desembarque da piramutaba no decorrer dos anos de 1999 a 2007 mostraram um pequeno aumento da produção para os estados do Amazonas e Pará, sendo que essa produção foi maior no ano de 2006. No estado do Pará, a produção pesqueira mostrou uma grande tendência de crescimento nos mesmos anos, mostrando que o desembarque efetuado nos frigoríficos do Pará é realizado principalmente pela frota industrial, que utiliza redes de arrasto no Estuário Amazônico. De acordo com os pescadores industriais, as redes de arrasto contribuem para o maior desembarque da frota industrial da piramutaba.

O Amazonas e o Pará são os estados que mais produzem pescado da região Norte. O Pará possui uma produção de 62.287,0 toneladas e apresentou um decréscimo de 13,4\% em 2007, em relação a 2006 (IBAMA, 2007). Ainda de acordo com o relatório do IBAMA, as espécies de peixes que mais contribuíram para este decréscimo foram: a piramutaba (Brachyplatystoma vaillantii) com 20,3\%, a dourada (B. rousseauxii) com 15,7\%, o mapará (Hypophthalmus marginatus) com 7,5\% e o filhote (B. filamentousum) com 7,3\%.

De acordo com os pescadores artesanais, se houver um aumento da frota piramutabeira ainda poderá haver um aumento na produção total trazendo em consequência uma redução na produtividade e nos estoques. A maioria dos pescadores artesanais de Vigia relatou que não está mais pescando a piramutaba em consequência da alta pressão da pesca industrial. Esses pescadores exploram agora a pescada gó (Macrodon ancylodon) e principalmente a pescada amarela (Cynoscion acoupa) em razão de estas espécies serem encontradas com maior abundância nas proximidades da costa da ilha do Marajó e na área do Salgado no estado do Pará.

Em decorrência da alta pressão que estes estoques vêm sofrendo, pescadores artesanais da área de estudo buscam alternativas como, por exemplo, a troca de espécies de peixe. E este padrão de comportamento de mudança de espécies, ocasionada pela redução de estoque, já foi observada para o tambaqui (Colossoma macropomum) por Petrere (1985) que era a principal espécie desembarcada em Manaus. Segundo Falabella (1994), essa espécie foi substituída pelo jaraqui (Semaprochilodus sp) como sendo o principal desembarcado. Segundo esse autor, este declínio foi devido ao excesso de exploração que levou à sobrepesca da espécie.

Os pescadores artesanais discorrem que as pescarias industriais estão acabando com o recurso através de duas, três e até cinco barcos industriais operando ao mesmo tempo na área do Estuário onde “[...] pegam tudo, desde 
o peixe de tamanho pequeno até o grande". Segundos os entrevistados, aqueles peixes que não têm importância comercial e/ou que são pequenos demais são devolvidos ao Estuário, com perfurações na bexiga natatória com o objetivo da espécie submergir e não voltar à tona a fim de burlar a fiscalização.

Por outro lado, os pescadores industriais do município de Vigia e do distrito de Icoaraci também associam a atividade artesanal ao declínio dos estoques, já que não existe lei para o limite de área de pesca artesanal. Alguns pescadores industriais relataram que as geleiras das pescarias artesanais invadem o local que é reservado para as pescarias industriais dificultando a atividade e também pescam a piramutaba de tamanho pequeno.

Segundo a opinião dos entrevistados, o aumento do poder de pesca contribuiu para a diminuição dos estoques, resultando em sobrepesca de crescimento. Estudos mostraram que nas capturas de piramutaba efetuadas pelas pescarias artesanais, no período de safra e entressafra, os peixes são capturados no tamanho entre $22 \mathrm{~cm}$ a $72 \mathrm{~cm}$, com média de 42,70 cm (BATISTA et al., 2005). Ainda de acordo com os mesmos autores, mais de $80 \%$ dos peixes amostrados tinham, em média, 3 a 4 anos de idade, e 58\% tinham 5 anos. Ainda de acordo com esse estudo, com frequência menor que $10 \%$, as piramutabas são capturadas com 1, 2, 6 e 7 anos de vida.

Conforme os registros do CEPNOR (2006), o número de barcos pesqueiros no Pará gira em torno de 6 mil unidades. O número de pescadores é de aproximadamente 30 mil para o litoral paraense (SETEPS, 2003). Ainda de acordo com os registros da CEPNOR, os auxílios do governo para viabilizar a obtenção de crédito destinado à compra de equipamentos de pesca podem ser responsáveis pelo aumento do número de barcos em atividade. As pescarias de subsistência perderam o caráter que tinham no passado para se tornarem uma atividade profissional. Além disso, o aparecimento de novas tecnologias introduzidas na Amazônia nas últimas três décadas contribuiu para a diminuição dos estoques pesqueiros como um todo (ISAAC, 2006). A explosão demográfica, sobretudo nos grandes centros urbanos amazônicos, fez com que houvesse um aumento da demanda pelo pescado, contribuindo para a intensificação da explotação dos principais estoques.

Os pescadores artesanais mais antigos relataram com saudosismo, as épocas antigas em que houve menor concorrência e mais piramutaba de grande porte. Isaac (2006) também relata que os pescadores lembram que houve menor concorrência e maiores rendimentos na atividade. A piramutaba já está sendo pescada no limite da sustentabilidade (BARTHEM, 1985) e os gestores entrevistados revelaram que a espécie vai continuar sendo sobre-explorados se não houver uma fiscalização severa. 
De acordo com Isaac (2006), imagina-se que o desenvolvimento da pesca na região siga os padrões das outras pescarias do Brasil e do mundo. A exemplo das pescarias da piramutaba, estudos realizados pela FAO em 2000 indicaram que $80 \%$ dos estoques pesqueiros mundiais se encontravam em estado de sobreexplotação ou estavam sendo explotados de modo pleno, $10 \%$ a mais do que tinha sido diagnosticado em 1995. As principais causas assinaladas para essa situação grave incluem o excesso de esforço de pesca, o desenvolvimento tecnológico e os subsídios econômicos.

\section{A gestão das pescarias da piramutaba}

Na recente história do Brasil, a elaboração de uma legislação da pesca de águas interiores teve início em 1912 e continuidade com a elaboração do Código da Pesca em 1938. Essa legislação foi revista após o nascimento da SUDEPE, pela Lei Delegada n 10, de 11 de outubro de 1962, quando foi publicado o Decreto-Lei no 221, no ano de 1967 (FISCHER, CHAGAS e DORNELLES, 1992; BARTHEM, 1999). A legislação que vigorou até a primeira década do século XXI foi baseada no Decreto-Lei no 221, no ano de 1967, que aborda aspectos da proteção e do estímulo à pesca, e no Decreto-Lei no $7679 / 1988$, que proíbe a pesca em períodos de reprodução. Estes decretos são válidos para águas interiores, mar territorial, zonas de alto mar, zona adjacente e plataforma submarina brasileira (ISAAC, ROCHA; MOTA, 1993).

O Decreto-Lei no 221/1967 tornou-se a base das ações legais na pesca, sendo também denominado Código de Pesca. Além das categorias ou modalidades de pesca, são constituídas as formas de obtenção de licenças e tipos de licenças para a atividade, bem como punições para o exercício de ações consideradas ilegais. Este decreto define também a indústria pesqueira como uma indústria de base (produz matéria-prima para outra empresa) e considera a captura de pescado como uma atividade agropecuária.

Várias disposições deste código sofreram mudanças por meio de novas normas, que alteraram formas ou prazos de incentivos fiscais e definiram regras para arredamentos e operação de embarcações ou sobre as obrigações das categorias de pescadores.

Conforme a antiga Secretaria da Aquicultura e Pesca, no dia do pescador, em junho de 2009, o presidente da República aprovou a Lei no 11.958 , que dispõe sobre a Política Nacional de Desenvolvimento Sustentável da Aquicultura e da Pesca. Regula as atividades pesqueiras e revoga a Lei $\mathrm{n}^{\circ} 7.679$, de 23 de novembro de 1988, e dispositivos do Decreto-Lei no 221, de 28 de fevereiro de 1967, e dá outras providências. Esta Lei, de 2009 , anula os artigos $1^{\circ}$ a $5^{\circ}, 7^{\circ}$ a 18,20 a 28 , 30 a 50,53 a 92 e 94 a 99. 
Esta Lei é bastante ampla e são citadas aqui algumas providências:

Art. $1^{\circ}$. Esta Lei dispõe sobre a Política Nacional de Desenvolvimento Sustentável da Aquicultura e da Pesca, formulada, coordenada e executada com o objetivo de promover:

i) O desenvolvimento sustentável da pesca e da aquicultura como fonte de alimentação, emprego, renda e lazer, garantindo-se o uso sustentável dos recursos pesqueiros, bem como a otimização dos benefícios econômicos decorrentes, em harmonia com a preservação e a conservação do meio ambiente e da biodiversidade; ii) O ordenamento, o fomento e a fiscalização da atividade pesqueira;

iii) A preservação, a conservação e a recuperação dos recursos pesqueiros e dos ecossistemas aquáticos;

iv) $\mathrm{O}$ desenvolvimento socioeconômico, cultural e profissional dos que exercem a atividade pesqueira, bem como de suas comunidades;

v) Pesca: toda operação, ação ou ato tendente a extrair, colher, apanhar, apreender ou capturar recursos pesqueiros.

Da atividade pesqueira:

Art. $5^{\circ}$. O exercício da atividade pesqueira somente poderá ser realizado mediante prévio ato autorizativo emitido pela autoridade competente, asseguradas:

i) A proteção dos ecossistemas e a manutenção do equilíbrio ecológico, observados os princípios de preservação da biodiversidade e o uso sustentável dos recursos naturais;

ii) A busca de mecanismos para a garantia da proteção e da seguridade do trabalhador e das populações com saberes tradicionais;

iii) A busca da segurança alimentar e a sanidade dos alimentos produzidos.

Art. $7^{\circ}$ o desenvolvimento sustentável da atividade pesqueira dar-se-á mediante:

i) A gestão do acesso e uso dos recursos pesqueiros;

ii) A determinação de áreas especialmente protegidas;

iii) A participação social;

iv) A capacitação da mão de obra do setor pesqueiro;

v) A educação ambiental;

vi) A construção e a modernização da infraestrutura portuária de terminais portuários, bem como a melhoria dos serviços portuários;

vii) A pesquisa dos recursos, técnicas e métodos pertinentes à atividade pesqueira;

viii) $\mathrm{O}$ sistema de informações sobre a atividade pesqueira;

ix) O controle e a fiscalização da atividade pesqueira;

x) $\mathrm{O}$ crédito para fomento ao setor pesqueiro.

Com base nas leis antigas e atuais, algumas portarias foram criadas, algumas delas tratando especificamente da pesca dos grandes bagres migradores.

No Brasil, as regulamentações específicas da pesca de bagres amazônicos estão limitadas à pesca industrial da piramutaba no Estuário (BARTHEM, 1999; VIEIRA, 2005). De acordo com Vieira (2005), essa regulamentação foi iniciada há duas décadas na tentativa de ordenar essas pescarias no Estuário por meio da Portaria de $\mathrm{n}^{\circ}$ 9, de 9 de março de 1983, através da antiga SUDEPE, que proíbe a atuação da frota pesqueira industrial ao sul do paralelo $00^{\circ} 05^{\prime} \mathrm{N}$ e do meridiano 
$48^{\circ} 00^{\prime}$ W. A referida portaria limitou o número de unidades de pesca (metros de malha, números de barcos, etc.), restringiu as capturas a uma cota máxima e regulamentou o tamanho da malha das redes de arrasto no saco túnel. Porém, essas medidas têm sido analisadas e transformadas ao longo dos anos através de instruções normativas publicadas pelo IBAMA.

A análise e alteração periódica da legislação são alguns dos passos principais para o sucesso do manejo como um todo, pois as características socioeconômicas e ambientais da pesca sofrem mudanças. Fatores determinantes para o sucesso da reprodução dos estoques e do bom desempenho econômico dos agentes da pesca incluem aqueles associados ao clima, ao pulso de inundação, à variação na demanda e inovações tecnológicas, dentre outros. No que diz respeito ao clima, podemos citar o aquecimento global e consequentemente o aumento da temperatura dos sistemas aquáticos e intensificação do fenômeno climático El Niño. O pulso de inundação deveria ser considerado, principalmente, devido à acentuação dos níveis máximo e mínimo do rio afetando o sucesso reprodutivo, a sobrevivência e os desembarques da espécie, além do acréscimo da demanda ocasionado pelo crescimento demográfico e pela necessidade dos empresários de aumentar a lucratividade.

$\mathrm{Na}$ opinião dos pescadores artesanais a atividade industrial é responsável por causar danos ambientais ao pesqueiro pelo arraste e suspensão de sedimentos do fundo e pela captura de indivíduos abaixo do tamanho mínimo e pelo descarte daqueles que não têm valor comercial. Barros e Ribeiro (2005), que realizaram estudos sobre a pesca de bagres, também relataram que os pescadores fazem crítica ao desperdício exagerado provocado pela frota industrial. Ainda de acordo com Barros e Ribeiro (2005), esse tipo de aparelho causa a morte de vários tipos e tamanhos de peixes que são rejeitados por não possuírem valor para a indústria. O descarte desse rejeito é realizado na área do Estuário, fazendo com que haja uma diminuição nos níveis de qualidade da água, gerada pelo material em decomposição.

Considerando que o Estuário é uma área de criação da piramutaba, recomenda-se estipular o número máximo da frota industrial e a suspensão da pesca de arrasto, estimular a captura com espinhéis e malhadeiras - pois são aparelhos de pesca de fácil controle de seletividade -, elaborar medidas de manejo dependendo do ciclo hidrológico, manter sempre a legislação atualizada, definir regras mais claras para os usuários desses recursos e aumentar a fiscalização. 


\section{CONCLUSÃO}

Por meio dos resultados obtidos desse estudo, pode-se concluir que:

Na percepção dos atores sociais da pesca, houve diminuição da produtividade da pesca industrial e artesanal da piramutaba nos últimos dez anos, embora os dados de desembarque indiquem um aumento na produção total no mesmo período;

Para pescadores, gestores e pesquisadores, nos próximos dez anos haverá diminuição dos estoques da piramutaba se não houver uma boa gestão das pescarias da espécie;

O ambiente estuarino como a principal área de criação e alimentação da piramutaba deve receber medidas especiais de proteção.

\section{AGRADECIMENTOS}

À Coordenação de Aperfeiçoamento de Pessoal de Nível Superior (CAPES) pela bolsa de estudo disponibilizada.

\section{REFERÊNCIAS}

ANON. O estado dos recursos pesqueiros: pesca extrativa e aquicultura. In: SANTOS, T.C.C.; CÂMARA, J.B.D. (Orgs.). GEO Brasil 2002. Perspectiva do Meio Ambiente no Brasil. Brasília: IBAMA, 2002. p. 133-147.

AVIZ, A. de. Empresas pesqueiras de Icoaraci - Pará: algumas considerações. Amazônia: Ci. \& Desenv., Belém, v 2, n. 3, jul./dez. 2006.

BARROS, J.F.; RIBEIRO, M. O. de A. Aspectos sociais e conhecimento ecológico tradicional na pesca de bagres. In: $\mathbf{O}$ manejo da pesca dos grandes bagres migradores: piramutaba e dourada no eixo Solimões-Amazonas. Manaus: IBAMA, Pró-várzea, 2005. 31p. (Coleção Documentos Técnicos: Estudos Estratégicos)

BARTHEM, R.B. O desembarque na região de Belém e a pesca na foz Amazônica. In: RUFFINO, M.L. A pesca e os recursos pesqueiros na Amazônia Brasileira. Manaus: ProVárzea, 2003. p. 137-167.

BARTHEM, R. B. A Pesca Comercial no Médio Solimões e sua Interação com a Reserva de Desenvolvimento Sustentável Mamirauá. In: QUEIROZ, H.; CRAMP, L.; WILLLIAM, G. R. (Orgs.). Estratégias para Manejo de Recursos Pesqueiros em Mamirauá. Belém: Sociedade Civil Mamirauá/CNPq, 1999. p. 72-107. 
BARTHEM, R. B.; GOULDING, M. Bagres balizadores: ecologia, migração e conservação de peixes amazônicos. Manaus: IPAAM, 1997. 130 p.

BARTHEM, R. B.; PETRERE JR, M. Fisheries and population dynamics of Brachyplatystoma vaillantii (Pimelodidae) in the Amazon Estuary. In: ARMANTROUT, N. B. (Ed.). Condition of the world's aquatic habitat. Proceedings of the World Fisheries Congress, Theme 1. Oxford; New Delhi: IBH Publishing, 1995. p. 329-340.

BARTHEM, R. B. Ocorrência, distribuição e biologia dos peixes da bacia do Marajó, estuário Amazônico. Bol. Mus. Para. Emílio Goeld, ser. Zoologia, v. 2, n.1, p. 49-69, 1985.

BATISTA, J. da S.; AQUINO, K. F. de; FARIAS, I. P.; GOMES, J. A. A. Variabilidade genética da dourada e da piramutaba na bacia Amazônica. In: FABRÉ, N. N.; BARTHEM, R. B. (Orgs.). O manejo da pesca dos grandes bagres migradores: piramutaba e dourada no eixo Solimões-Amazonas. Manaus: Ibama; ProVárzea, 2005, 114p. il.

CEPNOR. Centro de Pesquisa e Gestão de Recursos Pesqueiros do Litoral Norte. Relatório do censo estrutural da pesca de águas continentais na região Norte. Convênio ADA/UFRA No 018/2004. Belém: ADA; UFRA, 2006.

CHAVES, R. A.; SILVA, K. C. de A.; IVO, C. T. C.; CINTRA, I. H. A.; AVIZ, J. da S. Sobre a pesca da piramutaba, Brachyplatystoma vaillantii (valenciennes, 1940) em pescarias da frota industrial no estado do Pará. Bol. Téc. Cient. Cepnor, Belém, v.3, n.1, p. 163-177, 2003.

FALABELLA, P. A pesca no Amazonas: problemas e soluções. 2. Ed. Manaus: Imprensa Oficial do Estado, 1994. 180p.

FAO. Disponível em: <http://www.fao.org/fishery/statistics/global-captureproduction/en>. Acesso em: junho de 2010.

FISCHER, C. F. A.; CHAGAS, A. L. das; DORNELlES, L. D. C. Pesca de águas interiores. Brasília: IBAMA, 1992. 32p. (Coleção Meio Ambiente. Série Estudos: Pesca 2).

IBAMA. Estatística da Pesca Brasil. Grandes Regiões e Unidades de Federação Brasília: IBAMA, 2007.

IBAMA. Camarão Norte e Piramutaba. Brasília: IBAMA, 1997. 148p. (Coleção Meio Ambiente. Série estudos pesca, 9). 
ISAAC, V. J.; ROCHA, V.L.C.; MOTA, S. Considerações sobre a legislação da "Piracema" e outras restrições da pesca da região do Médio Amazonas. In: FURTADO, L.G.; LEITÃO, W.; FIÚZA de MELlO, A. (Orgs.). Povos das águas: realidade e perspectivas na Amazônia. Belém: Museu Paraense Emilio Goeldi, 1993. p. 187-211.

ISAAC, V. J. Explotação e manejo dos recursos pesqueiros do litoral amazonico: um desafio para o futuro. Ciência e Cultura, São Paulo, v.58, n.3, p. 33-36, 2006.

MEES, G. F. The Auchenipteridae and Oimelodidae of Suriname (Pisces, Nematognathi). Zool. Verh, Leiden, n.132, p.1-256, 1974.

MOURÃO, K. R. M.; PINHEIRO, L. A.; LUCENA, F. Organização social e aspectos técnicos da atividade pesqueira no município de Vigia - PA. Boletim do Laboratório de Hidrobiologia, v. 20, p. 39-52, 2007.

OLIVEIRA, D. M.; FREDÓU, T.; LUCENA, F. A pesca no Estuário Amazônico: uma análise uni e multivariada. Bol. Mus. Para. Emílio Goeldi. Ciências Naturais, Belém, v. 2, n. 2, p. 11-21, mai-ago. 2007.

PETRERE Jr., M. A pesca comercial no Rio Solimões-Amazonas e seus afluentes: Análise dos informes do pescado desembarcado no Mercado Municipal de Manaus (1976-1978). Ciência e Cultura, v. 37, 1985.

SANTOS, G. M. dos; SANTOS, A. C. M. dos. Sustentabilidade da pesca na Amazônia. Estudos avançados, São Paulo, v.19, n.54, 2005.

SETEPS. A pesca artesanal no estado do Pará: perfil sócio-econômico e organizacional dos pescadores filiados às colônias. Belém: SETEPS/Sine-PA, 2003.

SMITH, N. A pesca no rio Amazonas. Brasília: CNPq; Manaus: INPA, 1979. $154 \mathrm{p}$.

TORRES, M.; SILVA, M. L.; BUENNDIA, N. Gerenciamento de estoques pesqueiros na Amazônia: o caso da piramutaba. Monografia (Especialização CIPCTAM II) - Naea/UFPA, Belém, 1995.

VIEIRA, E. Legislação e plano de manejo para a pesca de bagres na bacia amazônica. In: In: FABRÉ, N. N.; BARTHEM, R. B. (Orgs.). O manejo da pesca dos grandes bagres migradores: piramutaba e dourada no eixo SolimõesAmazonas. Manaus: Ibama; ProVárzea, 2005, 114p. il.

WALMSLEY, S.; HOWARD, C.; MEDLEY, P. A. Participatory Fisheries Stock Assessement (ParFish) guidelines. London: MRAG, 2005. 
